Int. J. Morphol.,

35(4): 1422-1428, 2017

\title{
Palatal Rugae Characteristics and its Relationship with Angles Class 1, 2 \& 3 Malocclusions
}

\author{
Características de Rugas Palatinas y su Relación con Ángulos de Maloclusiónes Clase 1, 2 \& 3
}

\author{
Ibrahim Alshahrani
}

ALSHAHRANI, I. Palatal rugae characteristics and its relationship with angles class 1, 2 \& 3 malocclusions. Int. J. Morphol., 35(4):14221428, 2017.

SUMMARY: The objectives of the study were to, 1. Compare the accuracy of four methods of acquisition of palatal rugae (PR) characteristics (PRC). 2. Study the predominant PRC in Angles Class 1, 2, and 3 malocclusions. 3. To statistically correlate the predominant PRC with Class 1, 2 \& 3 malocclusions and thus explore the possibility of utilizing it in predicting malocclusions. Study casts and intraoral 3D scan images (3Shape ${ }^{\circledR}$ Intra-Oral Scanner) of the palate of 104 healthy orthodontic patients were included as Group I and Group II respectively. The casts of Group I were scanned using 3Shape ${ }^{\circledR}$ (Group III) and Sirona inEos X5 ${ }^{\circledR}$ (Group IV) cast scanners. PRC for all groups were recorded and PRC of Group I was compared with PRC of Groups II, III and IV for possible matching. 3D images of Group IV were further divided according to Angles classification and predominant PRC analyzed. $97.8 \%$ of PRC match was observed in Group I and Group IV. Wavy and complex rugae were predominant in Class 1 and 3 malocclusions and showed statistically significant difference between Class 1,2 and 3 malocclusions ( $\mathrm{p}=0.00$ and 0.014 respectively) with wavy being higher in Class 1 and complex being higher in Class 3 (LSD Post Hoc analysis). Direct intraoral 3D scanning and 3D scanning of the palatal area of casts are equally reliable methods for PR acquisition for examining PRC. All PRC considered together have a minimal impact on prediction of malocclusions, however, influence of wavy characteristic was maximum.

KEY WORDS: Palatal rugae; Malocclusion; Angle class I; Angle class II; Angle class III.

\section{INTRODUCTION}

Study of palatal rugae (PR) characteristics is a key area in any research involving rugoscopy and extensive literature is available on the different methods of acquisition of rugae. PR have been photographed directly (Stuart \& Goldstein, 2005) from the patient's palate or dental impressions made and casts poured (Hauser et al., 1989; Dawasaz \& Dinkar, 2013). Pictures of palate area of casts with a standardized angle of 450 has been successfully used for rugoscopy (Limson \& Julian, 2004). In both these methods, acquiring a 2D photograph of PR pattern was suitable for classifying PR. Symmetrograph of Korkhaus was used to measure tooth movement on study models by Peavy \& Kendrick (1967) and Lebret (1964) while the Reflex Metrograph was used to digitize ruga points in an X-Y-Z coordinate system (Almeida et al., 1995; Bailey et al., 1996). van der Linden (1978) used the Optocom to record 3D information of dental casts. Hoggan \& Sadowsky (2001) used a flatbed scanner to scan the casts and Corel Photo Paint to print the images of rugae. However, a 0-5\% magnification error was reported in this method. A slide caliper was used under a magnifying glass to measure the ruga directly on dental casts (Kapali et al., 1997). This method introduced significant error in evaluating rugae strength during measurement of anatomic points at different vertical levels. Rajcich \& Sadowsky (1997) used photocopies of maxillary casts to measure dental and palatal landmarks that also involved a significant $10 \%$ magnification error. Other digital methods involving 3D technology to record and analyze PR characteristics are sparse. Therefore, amongst the different methods available for PR acquisition, direct cast analysis is considered accurate for recording PR characteristics (PRC).

Palatal rugae are stable intraoral landmarks that are established in early intrauterine life. In unison, all the rugae create a pattern that has been studied for various purposes, published reports being mainly in the fields of Orthodontics, Forensic Odontology, Anthropology, Comparative Anatomy, Genetics, and Prosthodontics. They have been likened with fingerprints (Carrea, 1937) due to their stability that remains 
throughout life as well as their potential of regeneration after destruction with exactly the same pattern as before (Harrison, 1889). They have been used as reliable reference landmarks during orthodontic tooth movement (Hoggan \& Sadowsky, 2011). There have been studies on twins that revealed PRC are similar but not identical (Ritter, 1943). Thus, it can be said that PR pattern is established very early in life and the development and pattern are strongly governed by genetic effects. Since, teeth and PR anatomy develop during the same period of intrauterine life and genetics plays determining factor, it can be hypothesized that they bear relationship.

Dental malocclusions are third most commonly occurring oral conditions globally, and are widely prevalent $(42.8 \%)$ in Abha, Asir region of Saudi Arabia (al-Emran et al., 1990; Haralur et al., 2104). Genetic predisposition is the most frequently accepted etiology for this condition. Early diagnosis and interception of developing malocclusion can lead to high degree of acceptable prognosis with minimum orthodontic and surgical intervention (Tikare et $a l ., 2010)$. The popularly used classification for dental malocclusion is based on the relationship of maxillary and mandibular permanent first molars proposed by Angle (AlQarni et al., 2014). Angles classification, though considered as less versatile, is accepted as a reliable system that avoids intra-observer bias (Silva \& Kang, 2011). To the best of my knowledge, there is no report of the relationship of malocclusion types and specific rugae pattern. Hence, this study was designed in two parts with the aim of determining the most accurate digital method of PR acquisition (Part 1) and to explore the relationship of PRC with Angles Class 1, 2 and 3 malocclusions (Part 2). The specific objectives of the study were; 1 .To compare the accuracy of four methods of examining PRC. 2. To study the predominant PRC in Class 1,2 , and 3 malocclusions 3 . To statistically correlate the predominant PRC with Class $1,2 \& 3$ malocclusions and thus explore the possibility of utilizing it in predicting malocclusions.

\section{MATERIAL AND METHOD}

Prior to the commencement of the study, Ethical Clearance was obtained from Scientific Research Committee King Khalid University College of Dentistry (KKUCOD). Non-probability convenience sampling (purposive sampling) was employed in selecting the study group. During part 1 of the study, 147 systemically healthy Saudi male and female dental patients attending KKUCOD orthodontic clinics between December 2016 and May 2017 were screened. Out of the 147 screened patients 105 patients between the ages of 20 to 45 years, with normal palatal anatomy and having either Angles Class 1, 2 or 3 malocclusions (subdivisions not included) with no history of orthodontic or surgical treatment in the palate area were included. The included patients were dentate and had all the incisors, canines, premolars and first molars present. Patients with fixed or removable prosthesis and torus palatinus were not included. Maxillary arch alginate impressions (Cavex ${ }^{\circledR}$ Impression material) and intra-oral digital scans (Group II) of the palate (3Shape ${ }^{\circledR}$ Intra-Oral Scanner) were made. The alginate impressions were immediately poured with dental stone, trimmed and numbered to allow blind analysis of PR. The casts obtained from the alginate impressions (Group 1) were then scanned using two different 3D scanners, namely; 3Shape ${ }^{\circledR}$ (Group III) and Sirona inEos X5® (Group IV) cast scanners. After an initial screening, one cast was left out due to visible distortion of impression, hence 104 casts and their images were finally included in the study.

The study population was divided into four groups. Group I. Casts; Group II. 3Shape intra-oral direct scan images; Group III. 3-Shape cast scanner images and Group IV. Sirona inEos X5 cast scanner images. Single examiner recorded PRC using small case English alphabets based on the modified classification of Dawasaz \& Dinkar and Syed et al. (2016) (Table I). PRC for the casts (Group I) (Fig. 1) were examined by directly visualizing the palate area under adequate lighting conditions. The PRC obtained for this group were considered as ideal for comparison with groups II, III and IV. PRC for the 3D images (Groups II, III and IV) (Figs. 2, 3, 4) were examined by viewing the palate area of the images on the computer screen using the appropriate scanner software. The obtained data was entered in Microsoft Excel 2016 software (Microsoft Corporation, Redmond, MA, USA) and the recorded PRC of the casts (Group I) were compared with PRC of the 3D images of Groups II, III, IV respectively, for possible matching using the COUNTIF formula. The most accurate method with maximum matching was later used in the second part of the study to evaluate the predominant pattern.

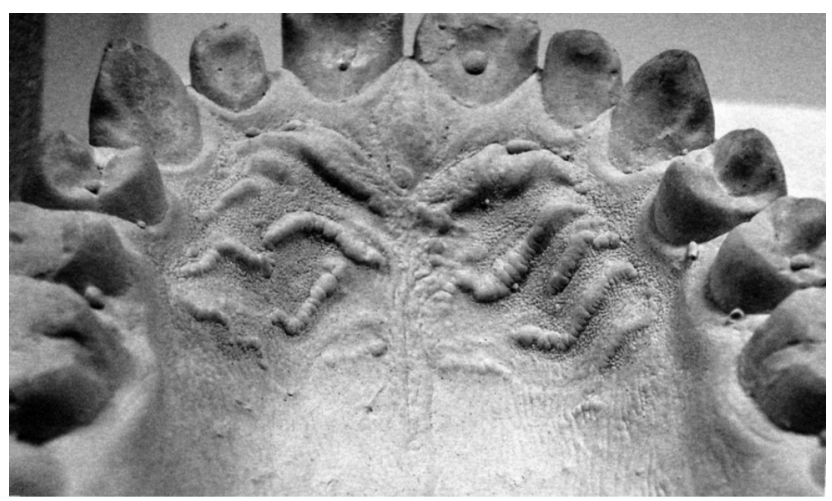

Fig. 1. Group I Cast. 

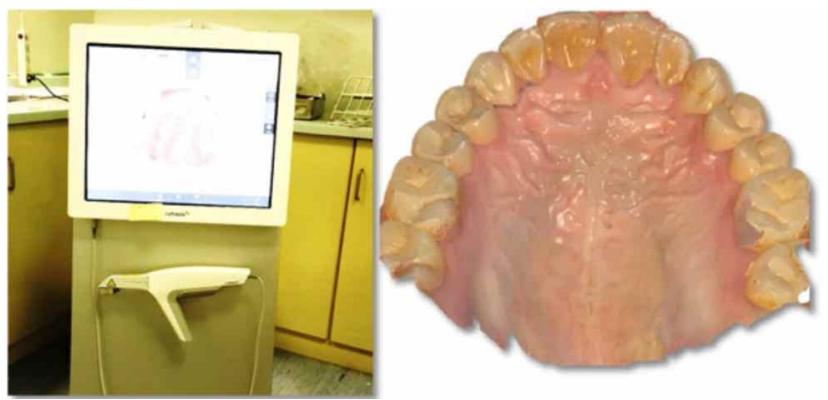

Fig. 2. Group II, 3shape Intra-oral scan image.
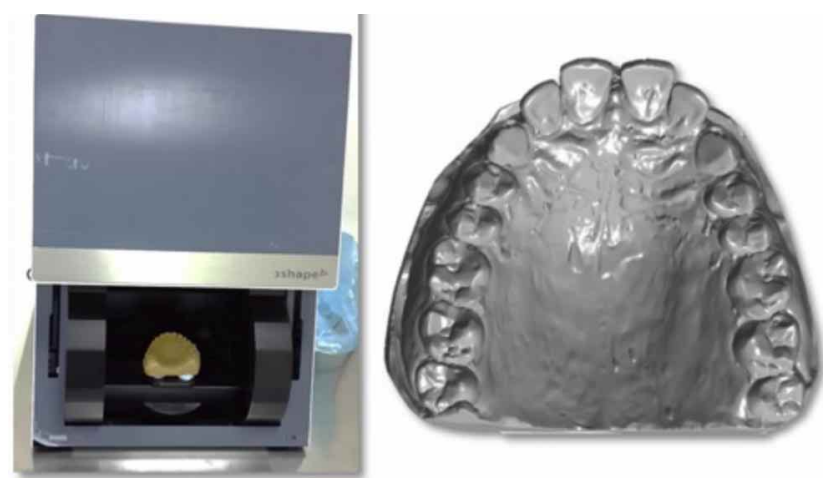

Fig. 3. Group III, 3shape cast scan image.

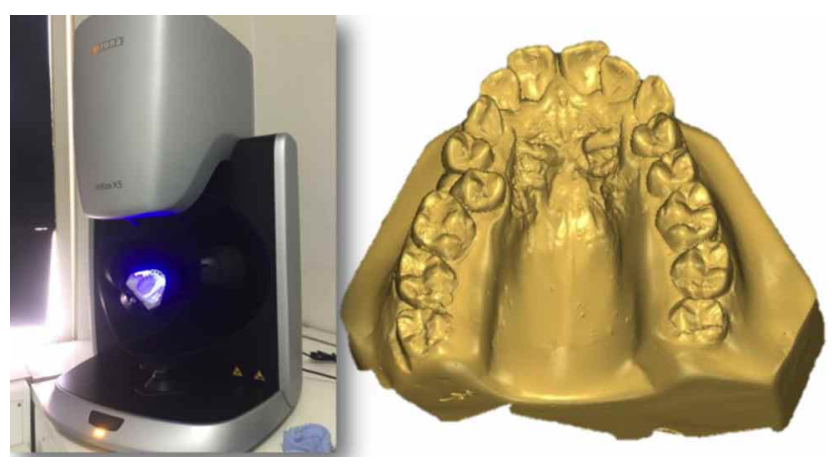

Fig. 4. Group IV, Sirona inEos X5 cast scan image.

In the second part of the study, Sirona inEos X5 scanner (Group IV) images were divided into three groups based on Angles classification of malocclusion. The data for classifying malocclusion was obtained from the patients' clinical records. PRC data of this group was entered in SPSS (version 10.0) software and statistically analyzed using ANOVA test to assess the predominant PRC in Class 1, 2 and 3 malocclusions. In addition, LSD post hoc analysis was employed to determine differences among dependent variables. Linear regression analysis was employed to correlate the predominant PRC within Class 1, 2 and 3 malocclusion groups.
Table I. Classification of palatal rugae.

\begin{tabular}{|c|c|c|}
\hline & Characteristics & Denoted as \\
\hline \multirow{9}{*}{$\begin{array}{l}\text { SIMPLE } \\
\text { RUGAE }\end{array}$} & Straight & a \\
\hline & Curve & $\mathrm{b}$ \\
\hline & Wavy & $\mathrm{c}$ \\
\hline & Annular & $\mathrm{d}$ \\
\hline & Papillary & $\mathrm{e}$ \\
\hline & Cross linked & $\mathrm{f}$ \\
\hline & Branch & $\mathrm{g}$ \\
\hline & Break & $\mathrm{h}$ \\
\hline & Converging & $\mathrm{i}$ \\
\hline \multirow{18}{*}{$\begin{array}{l}\text { COMPLEX } \\
\text { RUGAE }\end{array}$} & Diverging & $\mathrm{j}$ \\
\hline & Wavy + Annular & $\mathrm{k}$ \\
\hline & Wavy + Diverging & 1 \\
\hline & Curve + Diverging & $\mathrm{m}$ \\
\hline & Wavy + Papillary & $\mathrm{n}$ \\
\hline & Straight + Annular & o \\
\hline & Curve + Annular & $\mathrm{p}$ \\
\hline & Straight + papillary & q \\
\hline & Curve + papillary & $\mathrm{r}$ \\
\hline & Papillary + diverging & $\mathrm{s}$ \\
\hline & Curved + branched & $\mathrm{t}$ \\
\hline & Wavy + branched & $\mathrm{u}$ \\
\hline & Wavy + papillary + branch & $\mathrm{v}$ \\
\hline & Papillary + branch & $\mathrm{w}$ \\
\hline & Curve + break & $\mathrm{x}$ \\
\hline & Wavy + papillary + converging & $\mathrm{y}$ \\
\hline & Curve + converging & $\mathrm{z}$ \\
\hline & Branch + diverging & $\mathrm{az}$ \\
\hline
\end{tabular}

\section{RESULTS}

The total number of rugae observed in the study population were $783.96 .3 \%$ of rugae characteristics matched within the direct cast group (Group I) and in 3Shape intraoral 3D images group (Group II). Similarly, $96.8 \%$ rugae

Table II. Matching of PR Characteristics of Group I with Groups II, III and IV

\begin{tabular}{lccc}
\hline & Group II & Group III & Group IV \\
\hline Match & $96.3 \%$ & $96.8 \%$ & $97.8 \%$ \\
Mismatch & $1.2 \%$ & 0 & 0 \\
Missed & 2.4 & $3.2 \%$ & $2.2 \%$ \\
Total & $100 \%$ & $100 \%$ & $100 \%$ \\
\hline
\end{tabular}


characteristics matched within the direct cast group (Group I) and 3Shape cast 3D images group (Group III). The Sirona inEOS X5 cast 3D group (Group IV) and direct cast group (Group I) showed $97.8 \%$ matching of rugae characteristics. (Table II)

Mean value of wavy rugae in Class 1 malocclusion was 2.05, while in Class 2 and 3 they were 1.41 and 0.69 respectively. Mean value of complex rugae in Class 1,2 and 3 were $3.02,1.91$ and 3.19 respectively. At $95 \%$ confidence level a statistically significant difference (ANOVA) between Class 1, 2 and 3 malocclusions was observed when wavy $(\mathrm{p}=0.00)$ and complex rugae $(\mathrm{p}=0.014)$ were considered. At $99 \%$ confidence level wavy characteristic was found to be strongly significant $(\mathrm{p}=0.00)$. When the results were evaluated at $90 \%$ confidence level there were significant differences between Classes 1, 2 and 3 when the wavy, complex and total number of rugae $(\mathrm{p}=0.053)$ were considered (Table III). Statistically insignificant difference with respect to straight and curved rugae characteristics was found between the three malocclusion groups using ANOVA $(\mathrm{p}>0.05)$.

LSD Post Hoc analysis (Table IV) revealed a significantly higher wavy characteristic in Class 1 followed by Class 2 and Class 3. Similarly, complex characteristic is significantly higher in Class 3 compared to Class 1 and 2 malocclusions.
Linear regression analysis (Table $\mathrm{V}$ ) was employed to the available data using the formula as shown below:

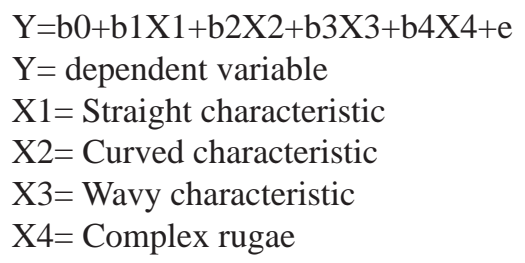

The results showed wavy characteristic influenced maximum on the prediction of malocclusion $(b 3=-0.664)$. Whereas, all PR characteristics together have a very minimum influence on malocclusion $(\mathrm{R} 2=0.289)$.

Numerical counting (Table VI) showed the almost same number of total rugae on the right and left the side of the palate. In addition, curved rugae are more on the left side and papillary rugae are more on the right side. The maximum number of rugae seen on the right side are eight, while the maximum number of rugae on the left side are six. Papillary characteristic is absent in first rugae of right as well as the left side. In the entire study population, the most predominant PRC is wavy on right side and curved on left side.

In Class 1 and 3 groups, the total number of rugae on the right side are more than on the left while in Class 2

Table III. Comparison of PRC between Class 1, 2 and 3 malocclusion groups by one-way ANOVA.

\begin{tabular}{cccccccccc}
\hline PR & Malocclusion & N & Mean & SD & Min & Max & df & F-value & P-value \\
\hline Straight & Class 1 & 44 & $1.39^{\mathrm{a}}$ & 0.993 & 0 & 4 & & & \\
& Class 2 & 34 & $1.76^{\mathrm{a}}$ & 1.257 & 0 & 5 & 2 & 1.526 & 0.222 \\
& Class 3 & 26 & $1.73^{\mathrm{a}}$ & 0.827 & 0 & 3 & & & \\
Curved & Class 1 & 44 & $1.55^{\mathrm{a}}$ & 1.044 & 0 & 4 & & & \\
& Class 2 & 34 & $2.03^{\mathrm{a}}$ & 1.291 & 0 & 5 & 2 & 1.889 & 0.157 \\
& Class 3 & 26 & $1.50^{\mathrm{a}}$ & 1.449 & 0 & 5 & & & \\
Wavy & Class 1 & 44 & $2.05^{\mathrm{a}}$ & 1.056 & 0 & 5 & & & \\
& Class 2 & 34 & $1.41^{\mathrm{b}}$ & 1.019 & 0 & 4 & 2 & 15.673 & $0.000^{*}$ \\
& Class 3 & 26 & $0.69^{\mathrm{c}}$ & 0.788 & 0 & 2 & & & \\
\multirow{5}{*}{ Total } & Class 1 & 44 & $3.02^{\mathrm{a}}$ & 1.947 & 0 & 7 & & & \\
& Class 2 & 34 & $1.91^{\mathrm{b}}$ & 1.960 & 0 & 9 & 2 & 4.419 & $0.014^{*}$ \\
& Class 3 & 26 & $3.19^{\mathrm{a}}$ & 1.744 & 0 & 7 & & & \\
& Class 1 & 44 & $8.02^{\mathrm{a}}$ & 1.759 & 5 & 14 & & & \multirow{6}{*}{. } \\
& Class 2 & 34 & $7.15^{\mathrm{b}}$ & 1.520 & 5 & 10 & 2 & 3.023 & 0.053 \\
& Class 3 & 26 & $7.19^{\mathrm{b}}$ & 2.020 & 2 & 11 & & & \\
\hline
\end{tabular}

*Statistically significant at $5 \%$ level.

IIDifferent characters in the superscript mean statistically significant difference by LSD post hoc test. 
Table IV. LSD Post Hoc test.

\begin{tabular}{|c|c|c|c|c|c|c|c|}
\hline \multirow{2}{*}{$\begin{array}{l}\text { Dependent } \\
\text { Variable }\end{array}$} & \multirow{2}{*}{$\begin{array}{l}\text { (I) } \\
\text { Malocclusion }\end{array}$} & \multirow{2}{*}{$\begin{array}{l}(\mathrm{J}) \\
\text { Malocclusion }\end{array}$} & \multirow{2}{*}{$\begin{array}{l}\text { Mean Difference } \\
\text { (I-J) }\end{array}$} & \multirow[b]{2}{*}{ Std. Error } & \multirow[b]{2}{*}{ Sig. } & \multicolumn{2}{|c|}{$95 \%$ Confidence Interval } \\
\hline & & & & & & Lower Bound & Upper Bound \\
\hline \multirow[t]{6}{*}{ Straight } & \multirow[t]{2}{*}{ Class 1} & Class 2 & -.378 & .240 & .118 & -.85 & .10 \\
\hline & & Class 3 & -.344 & .260 & .188 & -.86 & .17 \\
\hline & \multirow[t]{2}{*}{ Class 2} & Class 1 & .378 & .240 & .118 & -.10 & .85 \\
\hline & & Class 3 & .034 & .274 & .902 & -.51 & .58 \\
\hline & \multirow[t]{2}{*}{ Class 3} & Class 1 & .344 & .260 & .188 & -.17 & .86 \\
\hline & & Class 2 & -.034 & .274 & .902 & -.58 & .51 \\
\hline \multirow[t]{6}{*}{ Curved } & \multirow[t]{2}{*}{ Class 1} & Class 2 & -.484 & .282 & .090 & -1.04 & .08 \\
\hline & & Class 3 & .045 & .306 & .882 & -.56 & .65 \\
\hline & \multirow[t]{2}{*}{ Class 2} & Class 1 & .484 & .282 & .090 & -.08 & 1.04 \\
\hline & & Class 3 & .529 & .322 & .103 & -.11 & 1.17 \\
\hline & \multirow{2}{*}{ Class 3} & Class 1 & -.045 & .306 & .882 & -.65 & .56 \\
\hline & & Class 2 & -.529 & .322 & .103 & -1.17 & .11 \\
\hline \multirow[t]{6}{*}{ Wavy } & \multirow[t]{2}{*}{ Class 1} & Class 2 & $.634^{*}$ & .225 & .006 & .19 & 1.08 \\
\hline & & Class 3 & $1.353^{*}$ & .243 & .000 & .87 & 1.84 \\
\hline & \multirow[t]{2}{*}{ Class 2} & Class 1 & $-.634^{*}$ & .225 & .006 & -1.08 & -.19 \\
\hline & & Class 3 & $.719^{*}$ & .256 & .006 & .21 & 1.23 \\
\hline & \multirow[t]{2}{*}{ Class 3} & Class 1 & $-1.353^{*}$ & .243 & .000 & -1.84 & -.87 \\
\hline & & Class 2 & $-.719^{*}$ & .256 & .006 & -1.23 & -.21 \\
\hline \multirow[t]{6}{*}{ Complex } & \multirow[t]{2}{*}{ Class 1} & Class 2 & $1.111^{*}$ & .435 & .012 & .25 & 1.97 \\
\hline & & Class 3 & -.170 & .471 & .719 & -1.10 & .76 \\
\hline & \multirow[t]{2}{*}{ Class 2} & Class 1 & $-1.111^{*}$ & .435 & .012 & -1.97 & -.25 \\
\hline & & Class 3 & $-1.281^{*}$ & .496 & .011 & -2.26 & -.30 \\
\hline & \multirow{2}{*}{ Class 3} & Class 1 & .170 & .471 & .719 & -.76 & 1.10 \\
\hline & & Class 2 & $1.281^{*}$ & .496 & .011 & .30 & 2.26 \\
\hline \multirow[t]{6}{*}{ Total } & \multirow[t]{2}{*}{ Class 1} & Class 2 & $.876^{*}$ & .401 & .031 & .08 & 1.67 \\
\hline & & Class 3 & .830 & .434 & .059 & -.03 & 1.69 \\
\hline & \multirow[t]{2}{*}{ Class 2} & Class 1 & $-.876^{*}$ & .401 & .031 & -1.67 & -.08 \\
\hline & & Class 3 & -.045 & .457 & .921 & -.95 & .86 \\
\hline & \multirow[t]{2}{*}{ Class 3} & Class 1 & -.830 & .434 & .059 & -1.69 & .03 \\
\hline & & Class 2 & .045 & .457 & .921 & -.86 & .95 \\
\hline
\end{tabular}

*. The mean difference is significant at the 0.05 level.

Table V. Linear regression analysis with malocclusion as dependent variable.

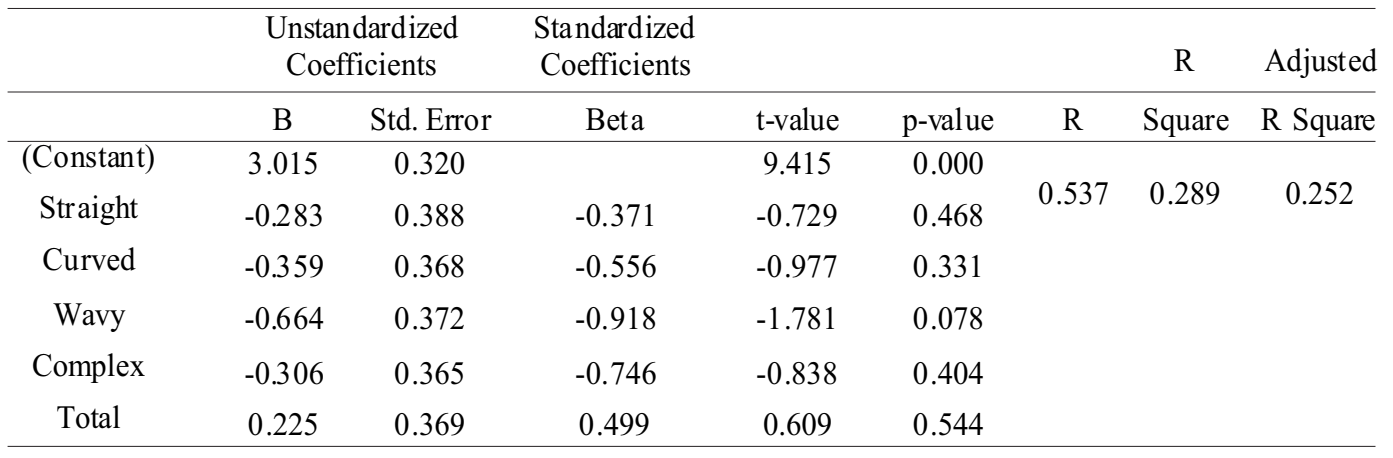

*Statistically significant at $5 \%$ level. 
Table VI. Number and predominance of PRC.

\begin{tabular}{|c|c|c|c|c|c|c|c|c|}
\hline & \multicolumn{2}{|l|}{ Class 1} & \multicolumn{2}{|l|}{ Class 2} & \multicolumn{2}{|l|}{ Class 3} & \multirow[b]{2}{*}{ Right } & \multirow[b]{2}{*}{ Left } \\
\hline & Right & Left & Right & Left & Right & Left & & \\
\hline Total number of rugae & 180 & 173 & 115 & 128 & 97 & 90 & 392 & 391 \\
\hline Predominant characteristic- Simple & Wavy & Wavy & Curved & straight & straight & Curved & Papillary & Curved \\
\hline Predominant characteristic - Complex & wavy+ & wavy+ & wavy+ & wavy+ & Curved+ & wavy+ & wavy+ & wavy+ \\
\hline & papillary & papillary & papillary & papillary & papillary & papillary & papillary & papillary \\
\hline
\end{tabular}

the total number of rugae are more on the left side. In Class 1 , the most predominant simple ruga is wavy $(25.5 \%)$, whereas wavy+papillary $(20.4 \%)$ is the most predominant complex ruga. Similarly, in Class 2 , the most predominant simple ruga is curved $(40.7 \%)$, whereas complex rugae are the least in this group. In Class 3 , the most predominant simple ruga is straight ( $24 \%)$, whereas curved+papillary $(9.6 \%)$ is the most predominant complex ruga. Combined or complex rugae are most common in Class $3(44 \%)$ compared to class $1(37.7 \%)$ and Class $2(26.8 \%)$. The most predominant complex ruga in the study population is a combination of wavy and papillary characteristics.

\section{DISCUSSION}

With advancements in CAD-CAM technology and 3D scanning, it is now possible to analyze the external morphology of PR up to the level of few microns. Comparison of dental casts and digital images for rugoscopy is not new (Goracci $e t$ al., 2016). Flügge et al. (2013) compared the accuracy of digital PR acquisition using different 3D scanners and found out that 3shape D250 scanner was more accurate than other similar scanners. It was observed that intra-oral scanning is somewhat less accurate than extra-oral scanning due to the presence of saliva and intra-oral space limitations. Likewise, we found that cast scanning has advantages over direct intraoral scanning. Cast scanning provides 3D images of the palate area without saliva bubbles to ensure proper visualization of PR and its associated structures. Intra-oral 3D scan images had saliva bubbles and shiny palatal surface obscuring rugae identification on a computer screen. However, the natural palate colour was an advantage for examining PRC in these images. In general, 3D scanning with all the three scanners used in our study was equally accurate for the purpose of rugoscopy. The most likely reason for the few differences in matching that occurred was probably due to the lack of improper viewing angle in the 3D software which requires a standardized 45-degree angulation of palate (Dawasaz \& Dinkar). This is easily possible with casts, hence, direct cast analysis was a preferred method of examining PR in the past. The biggest advantage of 3D images over casts is the ability to archive and transport 3D images.
Sidlauskas et al. (2003) studied the predicting factors of malocclusion in young children. Some of the factors proposed were age, period of the dentition, breathing pattern, presence of adenoids, family history of malocclusion, breastfeeding and its duration, pacifier sucking and its duration, and bottle-feeding and its duration. Factors such as the type of dentition, duration of pacifier sucking and anatomy of palate can affect the pattern of PR, therefore, it is possible PRC may bear a relationship with developing malocclusion. This has not been validated in scientific literature yet. However, results of our study reveal wavy and complex rugae characteristic influenced maximum for the prediction of malocclusion. Since PR pattern is established at a very early age the presence of numerous of wavy characteristic PR in a child can be a predictor of Class 1 malocclusion. Similarly, the predominance of wavy and complex characteristic can be a predictor for Class 3 malocclusion. Their strong correlation with malocclusion can be the focus of further investigation with different age groups and populations. The abundance of complex rugae on the right side points out towards the unilateral evolutionary development (Dawasaz \& Dinkar) of the palate in the study population. Side-wise analysis of PRC should also be analyzed in depth in future investigations. In addition, the need of technology to auto-detect PRC was felt during the examining of PR. Further studies could be undertaken to develop digital methods to auto-detect PRC and predict malocclusion.

Direct intraoral scanning and scanning of the palatal area of study models are equally reliable methods for rugoscopy. These images are easy to store and archive and can be transported digitally. All PRC considered together have a minimal impact on malocclusions, nevertheless, wavy characteristic influenced maximum on the prediction of malocclusion.

\section{ACKNOWLEDGEMENTS}

I would like to thank King Khalid University Deanship of Scientific Research for funding this research. I would also like to thank Dr. Syed Sadatullah, Dr. Ali Azhar Dawasaz and Dr. Rafi Ahmad Togoo for the immense help during the analysis and write up of this manuscript. 
ALSHAHRANI, I. Características de rugas palatinas y su relación con ángulos de maloclusiones clase 1,2 \& 3. Int. J. Morphol., 35(4):1422-1428, 2017.

RESUMEN: Los objetivos del estudio fueron los siguientes: 1. Comparar la precisión de cuatro métodos de adquisición de las características de la rugosidad palatina (CRP). 2. Estudiar las CRP predominantes en maloclusiones clases 1,2 y 3. 3. Correlacionar estadísticamente las CRP predominantes con maloclusiones clase 1, 2 y 3 e investigar la posibilidad de utilizarlas en la predicción de maloclusiones. Se incluyeron en el Grupo I y en el Grupo II, los moldes de estudio y las imágenes de barrido 3D intraoral (3Shape ${ }^{\circledR}$ Intra-Oral Scanner) del paladar de 104 pacientes ortodónticos sanos. Los escaneos del Grupo I se escanearon utilizando escáner fundidos 3Shape ${ }^{\circledR}$ (Grupo III) y Sirona inEos X5® (Grupo IV). CRP para todos los grupos se registraron y CRP del Grupo I se comparó con las CRP de los Grupos II, III y IV para una posible coincidencia. Las imágenes 3D del Grupo IV se dividieron de acuerdo con la clasificación de ángulos y las CRP predominantes analizadas. Se observó un 97,8 \% de concordancia en CRP en los grupos I y IV. Las rugas onduladas y complejas predominaron en las maloclusiones de Clases 1 y 3 y mostraron diferencias estadísticamente significativas entre las maloclusiones de Clases 1,2 y 3 ( $p=0,00$ y 0,014 respectivamente), siendo el ondulado más alto en la Clase 1 y el complejo en la Clase 3 (LSD Post Hoc). El escaneo 3D intraoral directo y el escaneado 3D del área palatal son métodos igualmente confiables para la adquisición de CRP para el examen de las CRP. Todas las CRP consideradas en conjunto tienen algún grado de impacto en la predicción de las maloclusiones, sin embargo, fue mayor la influencia de la característica ondulada.

PALABRAS CLAVE: Rugas palatinas; Maloclusión; Ángulo clase I; Ángulo clase II; Ángulo clase III.

\section{REFERENCES}

al-Emran, S.; Wisth, P. J. \& Böe, O. E. Prevalence of malocclusion and need for orthodontic treatment in Saudi Arabia. Community Dent. Oral Epidemiol., 18(5):253-5, 1990.

Almeida, M. A.; Phillips, C.; Kula, K. \& Tulloch, C. Stability of the palatal rugae as landmarks for analysis of dental casts. Angle Orthod., 65(1):43$8,1995$.

AlQarni, M. A.; Banihuwaiz, A. H.; Alshehri, F. D.; Alqarni, A. S. \& Alasmari, D. S. Evaluate the malocclusion in subjects reporting for orthodontic treatment among Saudi population in Asser Region. J. Int. Oral Health., 6(4):42-6, 2014.

Bailey, L. T.; Esmailnejad, A. \& Almeida, M. A. Stability of the palatal rugae as landmarks for analysis of dental casts in extraction and nonextraction cases. Angle Orthod., 66(1):73-8, 1996.

Carrea, J. U. La Identificación Humana por las Rugosidades Palatinas. Buenos Aires, Las Ciencias, 1937.

Dawasaz, A. A. \& Dinkar, A. D. Rugoscopy: predominant pattern, uniqueness, and stability assessment in the Indian Goan population. $J$. Forensic Sci., 58(6):1621-7, 2013.

Flügge, T. V.; Schlager, S.; Nelson, K.; Nahles, S. \& Metzger, M. C. Precision of intraoral digital dental impressions with iTero and extraoral digitization with the iTero and a model scanner. Am. J. Orthod. Dentofacial Orthop., 144(3):471-8, 2013.
Goracci, C.; Franchi, L.; Vichi, A. \& Ferrari, M. Accuracy, reliability, and efficiency of intraoral scanners for full-arch impressions: a systematic review of the clinical evidence. Eur. J. Orthod., 38(4):422-8, 2016.

Haralur, S. B.; Addas, M. K.; Othman, H. I.; Shah, F. K.; El-Malki, A. I. \& Al-Qahtani, M. A. Prevalence of malocclusion, its association with occlusal interferences and temporomandibular disorders among the Saudi sub-population. Oral Health Dent. Manag., 13(2):164-9, 2014.

Harrison, A. The palatal rugae in man. Proc. Acad. Nat. Soc., 6:245, 1889.

Hauser, G.; Daponte, A. \& Roberts, M. J. Palatal rugae. J. Anat., 165:23749, 1989.

Hoggan, B. R. \& Sadowsky, C. The use of palatal rugae for the assessment of anteroposterior tooth movements. Am. J. Orthod. Dentofacial Orthop., 119(5):482-8, 2001.

Hoggan, B. R. \& Sadowsky, C. The use of palatal rugae for the assessment of anteroposterior tooth movements. Am. J. Orthod. Dentofacial Orthop., 119(5):482-8, 2011.

Kapali, S.; Townsend, G.; Richards, L. \& Parish, T. Palatal rugae patterns in Australian aborigines and Caucasians. Aust. Dent. J., 42(2):129-33, 1997.

Lebret, L. Physiologic tooth migration. J. Dent. Res., 43:610-8, 1964.

Limson, K. S. \& Julian, R. Computerized recording of the palatal rugae pattern and an evaluation of its application in forensic identification. $J$. Forensic Odontostomatol., 22(1):1-4, 2004

Peavy, D. C. Jr. \& Kendrick, G. S. The effects of tooth movement on the palatine rugae. J. Prosthet. Dent., 18(6):536-42, 1967.

Rajcich, M. M. \& Sadowsky, C. Efficacy of intraarch mechanics using differential moments for achieving anchorage control in extraction cases. Am. J. Orthod. Dentofacial Orthop., 112(4):441-8, 1997.

Ritter, R. Z. Morphol. Anthropol., 40:367-72, 1943. In: Hauser, G.; Daponte, A. \& Roberts, M. J. Palatal rugae. J. Anat., 165:237-49, 1989.

Sidlauskas, A. \& Lopatiene, K. Prediction of malocclusion development based on the evaluation of the etiologic factors. Stomatologija, 5(1):226, 2003.

Silva, R. G. \& Kang, D. S. Prevalence of malocclusion among Latino adolescents. Am. J. Orthod. Dentofacial Orthop., 119(3):313-5, 2011.

Stuart, L. S. \& Goldstein, L. Forensic application of palatal rugae in dental identification. Forensic Exam., 14(1):44-7, 2005.

Syed, S.; Alshahrani, I.; Alshahrani, A.; Togoo, R. A.; Luqman. M. \& Dawasaz, A. A. Conversion of palatal rugae pattern to scanable Quick Response code in an Arabian population. J. Dent. Sci., 11(3):253-60, 2016

Tikare, S.; Rajesh, G.; Prasad, K. W.; Thippeswamy, V. \& Javali, S. B. Dermatoglyphics--a marker for malocclusion? Int. Dent. J., 60(4):3004, 2010.

van der Linden, F. P. G. M. Changes in the position of posterior teeth in relation to ruga points. Am. J. Orthod. Dentofacial Orthop., 74(2):14261, 1978.

Corresponding author:

Dr. Ibrahim Alshahrani

Associate Professor, Orthodontics

Department of Pediatric Dentistry and Orthodontic Sciences

King Khalid University College of Dentistry Abha

KINGDOM OF SAUDI ARABIA

Email: ishahrani@kku.edu.sa

Received: 16-07-2017

Accepted: 20-09-2017 